\title{
Mechanical Power of Leg Extensor Muscles in Male Boxing Players
}

Singh $^{1}$, Baljinder, Kumar ${ }^{2}$, Ashok \& Ranga ${ }^{3}$ M. D.

${ }^{1} \mathrm{PhD}$ Research Scholar, Department of Sports Science, Punjabi University Patiala-147001, Punjab, India

E-mail: bali007@rediffmail.com

${ }^{2}$ Assistant Professor, Department of Sports Science, Punjabi University Patiala-147001, Punjab, India

${ }^{3}$ Scientific Officer, Biomechanics Department, SAI NS NIS Patiala-147001, Punjab, India

\section{Abstract}

The present study was conducted on nineteen male boxing players (age: $16.37 \pm 1.34$ years) comprising of inmates of Sports Training Centre and Centre of Excellence scheme of Sports Authority of India, training at NS NIS Patiala (India). The aim of the study was to find the status of mechanical power variables of leg extensor muscles in male boxing players and to find the relationship between them. The experimental protocol developed by Bosco et al (1983), Mcguigan et al (2006) were used to measure the mechanical power variables of leg extensor muscles in male boxing players. Karl Pearson's coefficient of correlation was calculated with the help of SPSS version 9.0 software. The results of this study indicate that there was a highly significant correlation between the squat jump flight time, squat jump height, countermovement jump height, countermovement flight time, Eccentric Utilization Ratio (EUR), Elasticity Index (EI) and peak power $(0-15 \mathrm{sec})$, peak power $(45-60 \mathrm{sec})$ and Mean Power $(0-60 \mathrm{sec})$.

Key words: Mechanical Power, Vertical jump test, Leg Extensor Muscles, Muscular Power.

\section{Introduction}

Despite the increasing popularity of boxing, only a few studies have been conducted on the biomechanics of this sport. Compared with athletes engaged in other sport disciplines, boxers had similar explosive power as wrestlers and basketball players (Fleck, 1983). Coaches and trainers are greatly interested in developing training techniques designed to improve power performance of the legs and vertical jump ability (Blattner \& Stuart, 1980). Muscle force and lower extremity strength have a significant influence on executing competitive performance i.e. different technicaltactical demands in many sports (Ivanovic et al., 2011). As a result, adequate preparation of leg extensors is highly important especially in sports which involve different jumping techniques, frequent changes of direction in the frontal and lateral plane, numerous high

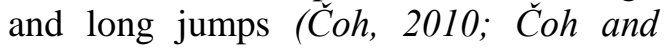
Babić, 2010). Many researchers (Zatsiorsky, 2006; Dopsaj et al., 2010) claim that diagnostics on physical preparation and athlete selection within the contractile abilities, verified with the basic parameters, i.e. using the level of maximal force development or explosive force, are very important for monitoring the effects of the training process from the aspect of basic indicators of contractile characteristic development. Strength is the ability to produce maximal force, which is considered a basic motor ability and contributes to high performance in most physical activities and sports for prevention of injury (Coyle et al, 1981, Pangrazi, 1999). Numerous studies of young athletes indicated that specific training in track and field, gymnastics, swimming, soccer, basketball improve vertical jumping performance, explosive 
strength of upper and lower limbs. Soccer (Gorostiaga et al, 2002), basketball (Foley, 1988, Klizning, 1991), volleyball (Mills et al, 2005), and tennis training (Huff, 1972, Liemohn, 1983) improve the explosive strength of lower limbs.

Very few studies have examined the effect of boxing training program on fitness characteristic in young athletes. Boxing is a very dynamic team sport, requiring continuous alterations of intensity and kinetic actions, and it is characterized by a great number of side movements, jumps, throws, and body contacts all of which strictly depend on muscular strength. Previous studies have reported that the high performance in many sporting endeavors is characterized by the ability to display high amounts of muscular power. Power is the product of muscular force and velocity or as an instantaneous value during a given movement. The latter, often referred to as peak power (PP), is typically associated with explosive movements such as sprinting, jumping and may be an important variable associated with success in a given discipline. The measurement of Peak Power by strength and conditioningcoaches is an important consideration in the training process. Changes in PP throughout the annual plan may be indicative of training status or adaptation to the workload and could be used to plan or adjust the training program based on the athlete's performance. The knowledge of mechanical power components of lower extremities of athletes can be of great interest for coaches and sport scientists to optimize explosive strength of the selected players. Therefore, the aim of the present study was to find the status of mechanical power of leg extensor muscles in male boxing players.

\section{Materials \& Methods}

Nineteen male boxing players (inmates of Sports Training Centre and Centre of Excellence scheme of Sports Authority of India, training at NS NIS Patiala, /(India) mean age of $16.37 \pm 1.34$ years; height of $176.32 \pm 7.84 \mathrm{~cm}$; body mass of $62.32 \pm 12.24 \mathrm{~kg}$ participated in the study. They were briefed of the purpose of the study and the experimental protocol (Bosco et al., 1983, Mcguigan et al., 2006) and the risks involved were also explained to each player and voluntary consent was taken from them. Each volunteer was first subjected to physical examination that included measurements of corporal data like date of birth, age, training age, height, body mass and sports discipline. The participants performed an adaptation process previous to the vertical jump test so that error could be minimized. The vertical jump test measurement system consisted of a portable hand-held computer unit connected to a contact mat (Swift Performance, New South Wales, Australia). It has been previously reported that the system is reliable compared with a force platform (Cronin et al., 2001).

Vertical Jump Tests: Three jumps Squat jump (SJ), Counter movement jump (CMJ) and Continuous vertical jump Test for 60 seconds (CVJT) were performed according to the experimental protocol (Bosco et al., 1983, Mcguigan et al., 2006).

Explosive strength and endurance variables: In this study, Eccentric Utilization Ratio (EUR) was calculated 
from vertical jump height $(\mathrm{CMJ} / \mathrm{SJ})$ or peak power $(\mathrm{CMJ} / \mathrm{SJ})$ by using Sayers et al (1999) peak power formula. Muscle Elasticity index was calculated from the jump height reached in CMJ and SJ Jumps (CMJ - SJ *100 / SJ) (Sayers et al., 1999). The explosive strength and endurance variables were power peak (PP), mean power (MP) and fatigue index (FI). Concerning the CVJT (continuous vertical jump test), the PP was estimated by the mechanical power produced in the first 15 seconds of a 60 -second work. The MP was estimated by the amount of work during a 60-second continuous effort. For $\mathrm{PP}$ and MP, the results were expressed in watts $/ \mathrm{kg}(\mathrm{W} / \mathrm{kg})$, as per the equation given by Bosco et al. (1983). The fatigue Index (FI) was calculated as the difference between the power peak (work produced in the first 15 seconds) and the mean power generated in the last 15 seconds of a continuous vertical jump work of 60 seconds relative to first 15 seconds peak power. The result was expressed in percentage $(\%)$.

\section{Test procedure and data collection:}

The participants were told to perform a 15-minute routine warm-up before performing the tests through stretching, running, coordination exercises and consecutive jumps (two sets of five vertical jumps). Three squat jumps (SJ) and three counter movement jumps (CMJ) were performed in random order on a jump mat connected to an electronic timer without the aid of an arm swing; this was standardized by having participants hold their hands on their hips. Two minutes rest period between attempts was established. The SJ involved the subject flexing the knee to approximately 90 degree maintaining the position for 3 seconds, and then jumping on the command "go." The CMJ was performed under the same conditions but involved flexion of the knee followed immediately by extension of the legs. Test was executed following the original protocol for both jumps (Sayers et al., 1999). On the next day, again the participants performed a 15-minute routine warm-up before the tests through stretching, running, coordination exercises and consecutive jumps (two sets of five vertical jumps). The participants were told to perform the continuous vertical jump Test (CVJT) during a work performed at maximal effort, with no pauses between jumps for 60 seconds. The subjects were told to keep chest in vertical position, with no excessive advance to avoid influence in the results; as well as to keep knees in extension during the flight, remaining with hands around waist. The participants were given stimulus to jump the highest as possible during the tests.

Statistical Analysis:

Mean and standard deviation for all the attributes age, height, body mass and biomechanical transients related to vertical jumps were calculated. Karl Pearson's coefficient of correlation was calculated with the help of SPSS version 9.0 software and the level of significance was kept as $\mathrm{p}<0.05$.

\section{Results \& Discussion}

Table 1: Mean \pm SD of Age, height \& body mass of male boxing players $(n=19)$

\begin{tabular}{ccc}
\hline Age, yrs & Height, cm & Mass, kg \\
\hline $16.37 \pm 1.34$ & $176.32 \pm 7.84$ & $62.32 \pm 12.24$
\end{tabular}


Table 2: Mean \pm SD of Mechanical power variables of the three vertical jump tests of male boxing players

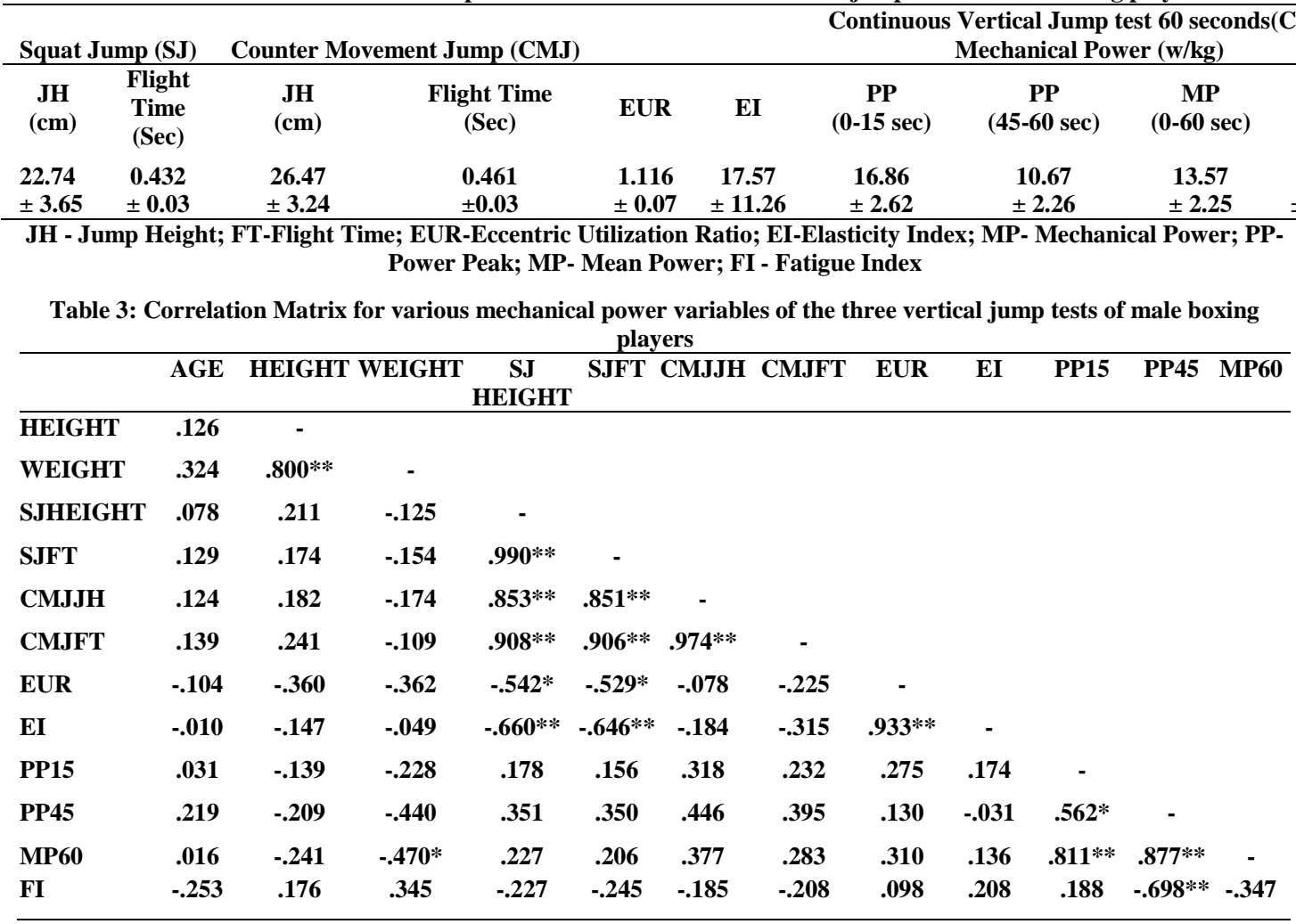

*significant at the 0.05 level; ** significant at the 0.01 level

JH - Jump Height; FT-Flight Time; EUR-Eccentric Utilization Ratio; EI-Elasticity Index; MP- Mechanical Power; PPPower Peak; MP- Mean Power; FI - Fatigue Index

The results of the present study (Table 3) demonstrate a close relationship between the various mechanical power variables of the three vertical jump tests (Squat jump, Counter movement jump and Continuous vertical jump test for 60 seconds) of male boxing players. Highly significant correlation was observed between the squat jump height and squat jump flight time, counter-movement jump height and counter-movement jump flight time at 0.01 level of significance. Significant negative correlation was observed between the squat jump flight time, squat jump height and Eccentric
Utilization Ratio (EUR), at 0.05 level of significance. Highly significant negative correlation was observed between the squat jump flight time, squat jump height and Elasticity Index (EI), at 0.01 level of significance. Highly significant correlation was observed between the Eccentric Utilization Ratio (EUR) and Elasticity Index (EI) at 0.01 level of significance. Significant correlation was observed between the Peak Power (0$15 \mathrm{sec}$ ) and Peak Power (45-60sec) at 0.05 level of significance. Highly significant correlation was observed between the Peak Power $(0-15 \mathrm{sec})$ and Mean Power $(0-60 \mathrm{sec})$ at 0.01 level of significance. 
Highly significant correlation was observed between the Peak Power (45$60 \mathrm{sec})$ and Mean Power $(0-60 \mathrm{sec})$ at 0.01 level of significance. Highly significant negative correlation was observed between the Peak Power (45-60sec) and Fatigue Index (FI) at 0.01 level of significance.

Francisco et al., (2010) reported average squat jump height $15.8 \pm 4.2 \mathrm{~cm}$, flight time $357 \pm 44.4 \mathrm{msec}$, countermovement jump height $16.9 \pm 4.8 \mathrm{~cm}$, flight time $369.0 \pm 49.9 \mathrm{msec}$ and elasticity index $7.1 \pm 3.2$ (age 11.32 \pm 1.82 years) in their study on male table tennis players. Whereas in the present study the average value of squat jump height $22.74 \pm 3.65 \mathrm{~cm}$, flight time 432 $\pm 30 \mathrm{msec}$, countermovement jump height $26.47 \pm 3.24 \mathrm{~cm}$, flight time $461 \pm 30 \mathrm{msec}$ and elasticity index $17.57 \pm 11.26$ was observed. The Eccentric Utilization Ration (EUR) has been suggested as a useful indicator of power performance in athletes. McGuigan et al., (2006) reported the average value of Eccentric Utilization Ration (EUR) of $1.03 \pm 0.20$ for male soccer players, $1.00 \pm 0.17$ for softball male players, $1.03 \pm 0.20$ for football male players \& $1.01 \pm 0.20$ for rugby male players, while in the present study the average value of EUR 1.116 \pm 0.07 has been observed. In the present study the average Mean Power (0-60sec) recorded during the vertical jump test for boxing players (age 16.37 \pm 1.34 years) was $13.57 \pm 2.25 \mathrm{w} / \mathrm{kg}$ whereas Bosco et al. (1983) found that average Mean Power (0-60sec) for school going Boys (age $17.3 \pm 0.8$ years) was $22.2 \pm 1.8 \mathrm{w} / \mathrm{kg}$. Jefferson et al., (2007) reported the average Peak Power (0-15sec) of $27.76 \pm 3.78 \mathrm{w} / \mathrm{kg}$, Mean Power (0-60sec)
$19.56 \pm 2.59 \mathrm{w} / \mathrm{kg} \&$ fatique index $(\%)(\mathrm{FI})$ $48.60 \pm 7.01$ in male volleyball players (age 19.01 \pm 1.36 years). In an another study by Jefferson et al., (2006) of the Intermittent vertical jump tests (IVJT), they reported the average Peak Power (0$15 \mathrm{sec})$ as $24.68 \pm 2.70 \mathrm{w} / \mathrm{kg}$, Mean Power (0-60sec) $18.79 \pm 2.23 \mathrm{w} / \mathrm{kg} \&$ fatique

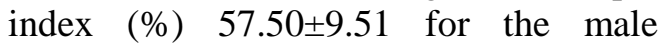
handball and basketball players (age of handball players 25.74 \pm 4.71 years \& basketball players 18.60 \pm 0.77 years). Whereas the in the present study the value of average Peak Power (0-15sec) $16.86 \pm 2.62 \mathrm{w} / \mathrm{kg}$, Peak Power (45-60sec) $10.67 \pm 2.26 \mathrm{w} / \mathrm{kg}$, Mean Power $(0-60 \mathrm{sec})$ $13.57 \pm 2.25 \mathrm{w} / \mathrm{kg} \&$ fatique index (\%) $36.39 \pm 11.96$ has been observed.

Conclusion: Based on the above considerations, the reported jumping test might offer the possibility of evaluating the mechanical power of the leg extensor muscles during explosive stretchshortening type exercises, which involve both metabolic and mechanical behaviour of skeletal muscles. The measurement of Peak Power by strength and conditioningcoaches is an important consideration in the training process. Changes in Peak Power throughout the annual plan may be indicative of training status or adaptation to the workload and could be used to plan or adjust the training program based on the athlete's performance.

\section{References}

Blattner Stuart, E. 1978. Relative effects of isokinetic and plyometric training on the vertical jump ability of college males. Publisher: MS Thesis, Kansas State University, 1-84.

Bosco, C., Luhtanen, P., Komi, PV. 1983. A simple method for measurement of mechanical power in jumping. European Journal of Applied Physiology, 50(2): $273-82$

Čoh, M. 2010. Biomechanical characteristics of take off action in high jump - a case study. Serbian Journal of Sports Sciences, 4(4): 127-135. 
Coyle, E., Feiring, D., Rotkis, T., Cote, T., Ruby, F., Lee, W., \& Wilmore, J. 1981. Specificity of power improvements through slow and fast isokinetic training. Journal of Applied Physiology, 51(6): 1437-1442.

Cronin, JB., McNair, PJ., Marshall, RJ. 2001. Relationship between strength qualities and motor skills associated with court performance. J. Hum. Mov. Stud., 40: 207-224.

Dopsaj, M., Blagojević, M., Koropanovski, N., \& Vučkovič, G. 2010. Structural analysis of basic leg extensor F-t curve characteristics in male athletes in different sports measured in standing position. In Duncan, M., \& Lyons, M. (Eds.): Trends in Human Performance Research (pp. 53-70). Nova Science Publisher. Inc., Hauppauge, NY, USA.

Fleck, S.J. 1983. Body composition of elite American athletes. Am. J. Sports Med. 11(6): 398-403.

Foley, J. 1988. In-season conditioning tips for basketball. Sport Light on Youth Sports, (10): 4 -14.

Francisco, P., Luís, C., \& Pablo, F. 2010. Muscular Power of Leg Extensor Muscles in Young Top-level Table Tennis Players. International Journal of Table Tennis Sciences, 6: 178-180.

Gorostiaga, E. M., Izquierdo, M., Ruesta, M., Inbarren, J. Gonzalez-Badillo, J., \& Ibanez, J. 2002. Effects of explosive type strength training on force production, sprint performance, endurance and serum hormones in soccer players. Medicine and Science in Sports and Exercise, 34(5), 37-45.

Huff, J. 1972. Auditory and visual perception of rhythm by performers skilled in selected motor activities. Research Quarterly, 43(2): 197-207.

Ivanović, J., Dopsaj, M., \& Nešić, G. 2011. Factor structure differences of indicators for evaluating isometric leg extensors explosive force in female volleyball athletes and different trained female population. British Journal of Sports Medicine, 45(6): 542.

Jefferson, E. H., Leonardo, G. S. N., Miguel, De A., César, A. D. 2007. Assessment of explosive strength-endurance in volleyball players through vertical jumping test. Rev. Bras. Med. Esporte, 13(3), 160e-163e.

Jefferson E. H., Leonardo G.S. N., and Miguel de A. 2006. Reliability of the four series 15-second vertical jumping test. Rev. Bras. Med. Esporte, 12(2): $85 \mathrm{e}-88 \mathrm{e}$.

Klizning, E. 1991. Training for improved jumping ability of basketball players. NSCA Journal, 13(3): 27-32.

Liemohn, W. 1983. Rhythmicity and motor skill. Perceptual and Motor Skills, 57(1): 327-331.

McGuigan, M.R., Doyle, T.L.A., Newton, M., Edwards, D.J., Nimphius, S., Newton, R.U. 2006. Eccentric utilization ratio: Effect of sport and phase of training. J. Strength Cond. Res. 20(4): 992-995.

Mills, J., Taunton, J., Mills, W. 2005. The effect of a 10week training regimen on lumbopelvis stability and athletic performance in female athletes: a randomized- controlled trial. Phys. Ther. Sport, 6(2): 60-66.

Pangrazi, R. 1999. Teaching elementary physical education. Boston, MA: Arizona State Univer. Physical Therapy in Sport, (6), 60-66.

Sayers, SP. Harackiewicz, D.V., Harman, E.A., Frykman, P.N., and Rosenstein, M.T. 1999. Cross-validation of three jump power equations. Med. Sci. Sports Exerc., 31(4): 572-77.

Zatsiorsky, V. M., \& Kraemer W. J. 2006. Science and practice of strength training (Second Ed.) Champaign, IL: Human Kinetics. 